\title{
MORPHOLOGICAL FEATURES OF RATS' HEARTS AFTER INTRAFETAL INJECTION OF DEXAMETHASONE
}

DOI:10.36740/WLek202102113

\author{
Olena A. Hryhorieva' ${ }^{1}$, Arthur V. Chernyavskiy' ${ }^{1}$ Yuriy Yo. Guminskiy ${ }^{2}$ \\ 'ZAPORIZHZHIA STATE MEDICAL UNIVERSITY, ZAPORIZHZHIA, UKRAINE \\ 2NATIONAL PIROGOV MEMORIAL MEDICAL UNIVERSITY, VINNYTSIA, UKRAINE
}

\begin{abstract}
The aim: Is to study the morphological features of rats' hearts after prenatal administration of glucocorticoids.

Materials and methods: In this study we used histological, immunohistochemical, electron-microscopic and statistical research methods.

Results: It is found that at $30^{\text {th }}$ day after birth in rats after intrafetal introduction of dexamethasone in myocardium a relative area occupied by arterial vessels is significantly smaller in comparison with control. Absolute and relative number of Ki- $67^{+}$-cardiomyocytes in the myocardium of experimental rats is reduced throughout the second week after birth and is significantly less compared to the control group. In the nuclei of cardiomyocytes of experimental rats is rendered the greater amount of heterochromatin in comparison with cardiomyocytes of the control group where euchromatin prevails.

Conclusions: After intrafetal injection of dexametazone changes in dynamics and significantly smaller index of relative area occupied by arterial vessels in ventricular myocardium at the 30th day after birth are observed; the absolute and relative number of Ki-67+ ${ }^{+}$-cardiomyocytes in myocardium decreases during the second week after birth and is significantly lower compared to the control group; in the nuclei of cardiomyocytes of experimental rats a greater amount of heterochromatin is visualized, and in cardiomyocytes of the control group - euchromatin.
\end{abstract}

KEY WORDS: cardiomyocytes, heart, dexamethasone

Wiad Lek. 2021;74(2):247-251

\section{INTRODUCTION}

The study of the causes and mechanisms of cardiovascular system diseases development is one of the topical issues of modern experimental medicine. The share of cardiovascular system pathology in the structure of mortality from non-communicable causes in Ukraine is about $67 \%$, and according to this criterion takes one of the first places in the world [1].

In the XX century, the English epidemiologist David Barker, formulated a theory according to which the conditions of intranatal development contribute to the formation of health and diseases in future [2]. In particular, it was found that adverse conditions in utero could program cardiovascular diseases in adulthood [3]. Morphological basis for the development of these conditions may be a syndrome of unclassified connective tissue dysplasia, which is manifested by disorganization of connective tissue fibers that gradually lead to decrease of adaptive possibilities of the body in future [4]. At that time adverse factors, can influence the morphogenesis of organs and systems during gestation, there may be drugs that women take during pregnancy, in particular, a synthetic glucocorticoid hormone dexamethasone.

According to "European guidelines for the management of premature newborns with respiratory distress syndrome" (2019), prenatal corticosteroid therapy is recommended for all women with threatened preterm labor before the $34^{\text {th }}$ week of pregnancy [5]. In particular, in Ukraine, according to the current clinical Protocol on obstetric care "Premature birth" (the
Ministry of health Order № 624 dated 03.11.2008), in case of the premature birth threat, the prevention of respiratory distress syndrome of the fetus from $24^{\text {th }}$ to $34^{\text {th }}$ week by intramuscular injection of dexamethasone is conducted. However, the appropriateness of the appointment of glucocorticoid hormones to pregnant women in the third trimester is a controversial issue according to potential negative long-term consequences [6]. Previously it is shown that intranatal introduction of glucocorticoids influences on different processes of connective tissue development: it is settled that in rats after glucocorticoid introduction in fetal period more earlier as compared to control thinning of articular cartilage, diminishing of relative area occupied by fibres in articular capsule, their disorganization, shortening and diminishing of depth of penetration in the matrix of articular cartilage of the joined bones, more later as compared to control appearance of elastic fibres in articular capsule are defined [7]; a significant increase of the relative area occupied by intertrabecular lacunas in subchondral bone compared to control is revealed [8].

In particular, there is a connection between prenatal exposure to synthetic glucocorticoids and an increased risk of developing cardiovascular disease further in adulthood [9].

In rodents physiological increase in the synthesis of endogenous glucocorticoids by mothers' adrenal glands starts at the 15th day of pregnancy, in humans - during the last week before birth. On the other hand, the level of placental 11-beta-hydroxysteroiddehydrohenase (11 $\beta$-HSD) decreases during the last 
week of pregnancy both in rodents and humans, which leads to the passage of maternal glucocorticoids to the fetus by the end of pregnancy and provides functional maturation of organs and systems [10]. However, dexamethasone is not metabolized by $11 \beta-H S D$, and it can pass freely through the placental barrier during the embryonic period from mother to fetus [11]. In experiments with animals it was found that the effect of glucocorticoids in late pregnancy led to structural maturation of the fetal heart by increased proliferation of cardiomyocytes at the 19-th and 21-th day of fetal development [12].

However, the morphological features of rats' hearts after prenatal administration of glucocorticoids are still need to be reviewed.

\section{THE AIM}

The aim of the research is to study the morphological features of rats' hearts after intrafetal injection of dexamethasone.

\section{MATERIALS AND METHODS}

The object of the study was 144 heart of white laboratory rats, which were divided into 3 groups: the $1^{\text {st }}$ - group of intact animals; the $2^{\text {nd }}$ group consisted of experimental animals, each of which at the $18^{\text {th }}$ day of fetal development was injected by $0.05 \mathrm{ml}$ of dexamethasone; the $3^{\text {rd }}$ group of control rats, which were injected by $0.05 \mathrm{ml}$ of $0.9 \% \mathrm{NaCl}$ at the $18^{\text {th }}$ day of intranatal development. The formation of a control group of rats is due to the need to eliminate the influence of surgical intervention in the prenatal period on the obtained changes in the experimental group.

Animals were contained in standard conditions of vivarium according to "European Convention for the protection of vertebrate animals used for experimental and other scientific purposes" (Strasbourg, 18.03.86 G.) and the Law of Ukraine № 1759-VI (15.12.2009) On the Protection of Animals from Cruelty. Morphological structure of heart was examined at days $1^{\text {st }}, 3^{\text {rd }}, 5^{\text {th }}, 9^{\text {th }}, 14^{\text {th }}, 21^{\text {th }}, 30^{\text {th }}$ and $45^{\text {th }}$ after birth. Fixation of histological material was carried out in $10 \%$ neutral formaldehyde. Immunehistochemical, histological methods, method of electron microscopy and statistic methods were used in the work.

Serial histological sections $4 \mu \mathrm{m}$ in thickness after dewaxing were stained by hematoxylin and eosin according to standard techniques, all samples were embedded in the balm. Photos of histological samples were conducted using CarlZeiss software (AxioVision 4.8). Calculation of the relative area that is occupied by the arterial vessels in ventricles of rats was performed using the electronic program ImageJ with an overlay of masks. Percentage values were obtained as the ratio of the number of pixels that corresponded to the studied structures that are specifically colored, to the total number of pixels in the digital image of the sample, with the data obtained in the area of $9000 \mu \mathrm{m} 2$. For electron microscopy, ultra-thin sections of myocardial fragments of the ventricles of the heart were made, they were counterstained with lead citrate according to the Reynolds method and examined in an electron microscope
PEM-100-01 at an accelerating voltage of $75 \mathrm{kV}$. To detect proliferating cardiomyocytes immunohistochemical studies were performed using Ki-67: sc-23900 mouse monoclonal antibody (Santa Cruz Biotechnology, inc.). Immunohistochemical reaction was visualized using an UltraVision Quanto HRP + DAB System from Thermo Scientific, followed by photodocumentation and processing in Image). The amount of Ki-67 + -cardiomyocytes was counted per $105 \mu \mathrm{m} 2$ of the ventricles of the heart of animals.

Analysis of the obtained results was conducted by means of statistical methods with the use of computer license program «Statistica for Windows 13» (StatSoft Inc., № JPZ804I382130ARCN10-J). The statistical significance of the obtained differences of indicators in the comparison groups was evaluated using the Mann-Whitney $U$ test and considered to be significant at $p<0.05$, that is generally accepted for biological and medical researches. The numerical data of the obtained results are presented as $\mathrm{M} \pm \mathrm{m}$ (arithmetic mean \pm standard error of the mean).

Ethnical approval. Supporting and withdrawal of animals from experiment was carried out in accordance with the requirements of the European Commission Directive (86/609/ EEC), Law of Ukraine № 1759-VI (15.12.2009) On the Protection of Animals from Cruelty.

\section{RESULTS}

The dynamics of the relative area occupied by arterial vessels in myocardium of intact and control animals changes wavy with a maximum value at the 30th day $-6,92 \pm 2,21$ and $7,05 \pm 1,67 \%$, respectively (Table I).

In animals of intact group, this index increases gradually just from birth up to the $30^{\text {th }}$ day multiplying in 5.25 times with maximum increase at the fifth day (in 2.07 times), and then reduces by $40.75 \%$. The relative area of arterial vessels in myocardium of control animals runs up in 5 times by the end of the first month of observation, later on at $45^{\text {th }}$ day it decreases by $36.59 \%$. The value of this index in intakt and control groups of animals were not significantly different in all periods of observation.

Dynamics of the relative area occupied by arterial vessels in myocardium of experimental animals after intrauterine injection of dexamethasone differs from data of intact and control groups: maximum value $(4,28 \pm 1,26 \%)$ is revealed at the 14th day after birth. Overall, the value of this index in experimental group of animals increases in 1.95 times during the first 2 weeks after birth. Then it gradually reduces up to 45 days by $24.3 \%$, and at the 30th day of life, the relative area occupied by arteries in myocardium of experimental animals is significantly lower compared to the values of the control group (3.34 $\mathrm{a} \pm 1,18$ and $7.05 \pm 1,67 \%$, respectively).

In ventricular myocardium of rats' heart of all groups of animals we define cardiomyocytes which express the Ki-67 antigen on the membrane of their nuclei (Fig. 1).

At day $9^{\text {th }}$ after birth in experimental animals, the absolute number of $\mathrm{Ki}-67^{+}$cardiomyocytes in myocardium was $200.0 \pm 12.8$ cells per $10^{5} \mu \mathrm{m}^{2}$ that index was significantly lower in comparison with control $-248.0 \pm 14.4$. In the 
Table I. The relative area occupied by arterial vessels in myocardium of animals $(M \pm m, \%)$

\begin{tabular}{cccc}
\hline & Intact group of animals & Experimental group of animals & Control group of animals \\
\hline $1^{\text {st }}$ & $1,32 \pm 0,49$ & $2,19 \pm 1,13$ & $1,41 \pm 0,49$ \\
\hline $3^{\text {rd }}$ & $1,77 \pm 0,54$ & $2,73 \pm 0,75$ & $1,98 \pm 0,74$ \\
\hline $5^{\text {th }}$ & $3,68 \pm 1,09$ & $3,19 \pm 1,04$ & $3,30 \pm 0,92$ \\
\hline $9^{\text {th }}$ & $4,51 \pm 1,75$ & $3,70 \pm 0,97$ & $4,44 \pm 1,25$ \\
\hline $14^{\text {th }}$ & $4,77 \pm 1,61$ & $4,28 \pm 1,26$ & $5,04 \pm 1,22$ \\
\hline $21^{\text {st }}$ & $5,37 \pm 1,36$ & $3,79 \pm 1,20$ & $5,48 \pm 1,84$ \\
\hline $30^{\text {th }}$ & $6,92 \pm 2,21$ & $3,34 \pm 1,18^{*}$ & $7,05 \pm 1,67$ \\
\hline $45^{\text {th }}$ & $4,10 \pm 1,18$ & $3,24 \pm 1,18$ & $4,47 \pm 0,83$ \\
\hline
\end{tabular}

*-result is reliable in relation to control group $(p<0,05)$.
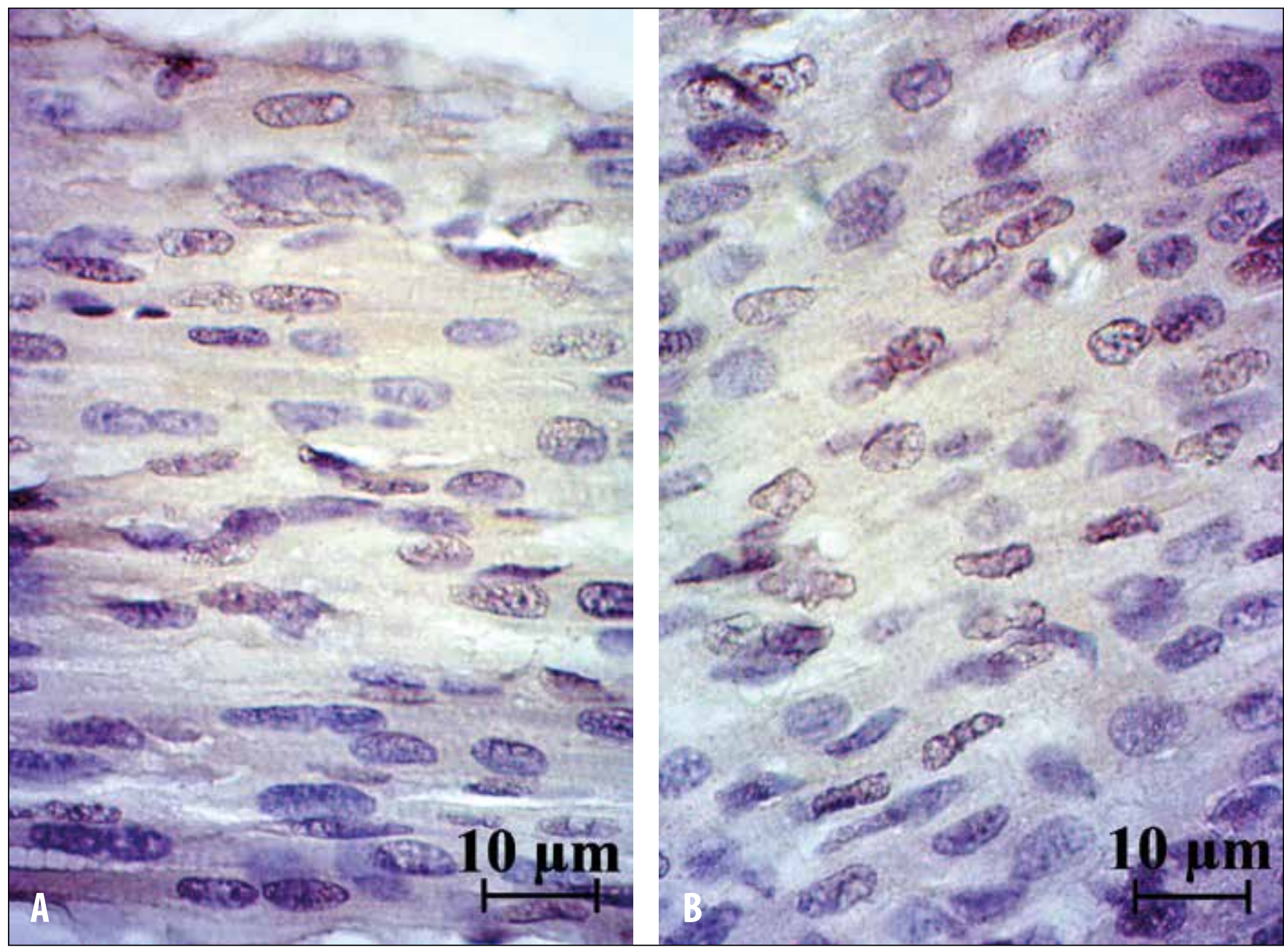

Fig 1. Ki-67+-cardiomyocytes in myocardium of left ventricle of control rat. X 1000. A) the 9th day after birth, b) the 14th day after birth.

group animals after intrafetal injection of dexamethasone the relative number of Ki-67 + cardiomyocytes to the total number of cells in the area of view was also significantly lower compared to the data of the control group (18.4 \pm 1.2 and $26.4 \pm 1.2 \%$, respectively).

At day $14^{\text {th }}$ after birth the absolute number of $\mathrm{Ki}-67^{+}$ cardiomyocytes in the group of animals after intrafetal injection of dexamethasone decreases by $36.8 \%$, compared to the previous observation period and is 126.4 \pm 3.2 cells per $10^{5} \mu \mathrm{m}^{2}$ and is significantly lower than in control rats $\left(297.1 \pm 22.4\right.$ cells per $\left.10^{5} \mu \mathrm{m}^{2}\right)$. The relative number of Ki-67 + -cardiomyocytes in the experimental group was also significantly lower compared to the values of the control group $(16.7 \pm 1.0 \%$ and 26.2 $\pm 1.5 \%$, respectively).

Electron microscopy revealed that the greater amount of heterochromatin is visualized in the nuclei of cardiomyocytes of rats after intrafetal injection of dexamethasone, and in cardiomyocytes of animals of the control group euchromatin prevails (Fig. 2). 


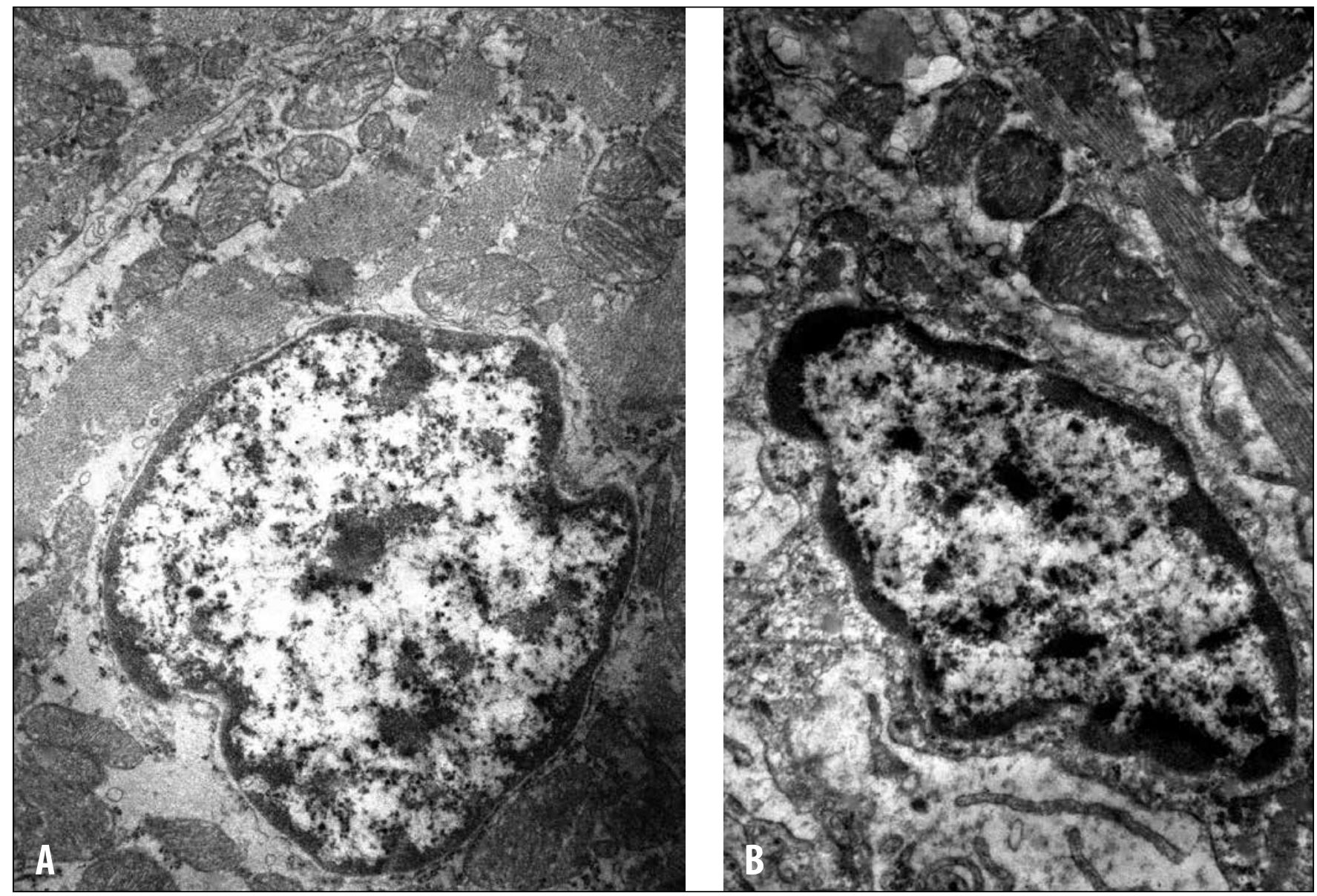

Fig 2. Myocardium of rats' left ventricle at day 14th after birth. Nucleus of cardiomyocyte. X 7500. A) control rat; b) rat after intrafetal injection of dexamethasone.

\section{DISCUSSION}

Dynamics of the relative area occupied by arterial vessels in the ventricular myocardium of intact and control rats, within 45 days of postnatal life, consistent with the views of Kok Wah Hew (2003), postulating that morphogenesis of arterial vessels in rats lasts for a month after birth [13]. After intrafetal injection of dexamethasone a premature maturation of the vascular component of the myocardium is established proved by changing in ratio towards earlier cessation of increasing of relative area occupied by arteries. Such changes are consistent with the literature data according the ability of dexamethasone to inhibit proliferation of smooth muscle musculature of the arteries, which leads to their premature maturation [14]. Together with previously obtained data on the reduction of the thickness arterial wall complex intima-media in myocardium after intrafetal injection of dexamethasone, these changes can lead to vascular dysfunction of heart in future.

Previously, we have described changes in nuclear-cytoplasmic relations in myocardium of rats after intrafetal injection of dexamethasone. [15]. It is found that in the experimental group the number of cardiomyocytes' nuclei intensively increases during the first five days after birth, after that myocardium thickens due to increased sizes of cardiomyocytes not due to increased their number. Obtained results of the study are consistent with earlier data on the participation of dexamethasone in premature maturation of the heart. The number of Ki- $67^{+}$-cardiomyocytes in myocardium of intact and control animals increases from $9^{\text {th }}$ up to $14^{\text {th }}$ day after birth and corresponds to the period of terminal cardiomyocytes' binucleation, which in rats lasts for two weeks after birth. The decrease in number of $\mathrm{Ki}-67^{+}$-cardiomyocytes in the heart of rats after intrafetal injection of dexamethasone during the second week after birth indicates a premature decrease of proliferative activity of cardiomyocytes, i.e., early maturation of myocardium. Transmission electron microscopic study of cardiomyocytes' nuclei of ventricular myocardium confirms this assumption. In fact, revealed increasing amount of heterochromatin at day $14^{\text {th }}$ after birth in experimental group, while in the nuclei of cardiomyocytes of control animals a greater amount of euchromatin is revealed. That is, in rats after intrafetal injection of dexametazone at the fourteenth day after birth cardiomyocytes are incapable of mitotic division, whereas in control group this possibility still remains. Thus, dexamethasone leads to appearance of premature binuclear cardiomyocytes, which potentially reduces the number of functional units of the heart, which in future will have more intense growth to develop a sufficient power of contraction due to the greater load on exact cells [16]. This may lead to compensatory hypertrophy and reduced adaptive capacity of myocardium, which in future will increase the risk of coronary heart disease. All this indicates the ability of prenatal dexamethasone to program cardiovascular disease in adulthood. 


\section{CONCLUSIONS}

1. After intrafetal injection of dexametazone changes in dynamics and significantly smaller index of relative area occupied by arterial vessels in ventricular myocardium at the 30th day after birth are observed.

2. After intrafetal injection of dexametazone the absolute and relative number of $\mathrm{Ki}-67^{+}-$cardiomyocytes in myocardium decreases during the second week after birth and is significantly lower compared to the control group.

3. In the nuclei of cardiomyocytes of the rats' heart after intrafetal injection of dexametazone, a greater amount of heterochromatin is visualized, and in cardiomyocytes of the control group - euchromatin.

4. The revealed changes indicate premature maturation of cardiomyocytes after intrafetal injection of dexametazone, which reduces their number in future life.

\section{REFERENCES}

1. Gandzyuk V.A., Dyachuk D.D., Kondratyuk N. Yu. Dynamica zahvoryuvannosti ta smertnosti vnaslidok hvorob systemi krovoobigu $\checkmark$ Ukraine. [Dynamics of morbidity and mortality due to blood circulatory diseases in Ukraine (regional aspect)]. Bulletin of Problems Biology and Medicine. 2017;2:319-323. (In Ukrainian).

2. Rodriguez-Caro H., Williams S. Strategies to reduce non-communicable diseases in the offspring: Negative and positive in utero programming. J. Dev. Orig. Health Dis. 2018; 9(6):642-652. D0I : 10.1017/ S2040174418000569.

3. Miranda J.0., Ramalho C., Henriques-Coelho T. et al. Fetal programming as a predictor of adult health or disease: the need to reevaluate fetal heart function. Heart Fail Rev. 2017;22(6):861-877. D0I : 10.1007/ s10741-017-9638-z.

4. Voloshyn N.A., Grygorieva E.A. experimental'naya model' razvitiya syndrome nedifferentsirovannoy dysplasia soedinitel'noy tkani [An experimental model for the development of undifferentiated connective tissue dysplasia syndrome]. Pathology. 2009;6(1):39-42. (In Russian).

5. Briceño-Pérez C., Reyna-Villasmil E., Vigil-De-Gracia P. Antenatal corticosteroid therapy: Historical and scientific basis to improve preterm birth management. Eur. J. Obstet. Gynecol. Reprod. Biol. 2019;234: 32-37. D01: 10.1016/j.ejogrb.2018.12.025.

6. Karlsson L., Barbaro M., Ewing E. et al. Epigenetic Alterations Associated With Early Prenatal Dexamethasone Treatment. J. Endocr. Soc. 2018;3 (1):250-263. DOl : 10.1210/js.2018-00377.

7. Hryhorieva $0 . A$. Osoblivosti reactivnosti kolinnogo sugloba na tli dii gidrocortizonu v plidnomu periodi [Peculiarities of rats' knee joint reactivity on the background of hydrocortisone influence during fetal period]. Actual questions of medical science and practice. 2015; 82(2): 48 - 55. (In Ukrainian).

8. Grigorieva E.A., Monina E.V. Osobennosti reaktivnosti subhondralnoy kosti kris v rannem postnatalnom periodi posle vvedeniya gidrokortizona beremennym [Features of reactivity of rats' subchondral bone in the early postnatal period after administration of hydrocortisone to pregnant]. World of Medicine and Biology. 2014;4(47):104-107. (In Russian).

9. Song R., Hu X.Q., Zhang L. Glucocorticoids and programming of the microenvironment in heart. J. Endocrinol. 2019;242(1):121-133. D0I : 10.1530/J0E-18-0672.
10. Murphy M.O., Cohn D.M., Loria A.S. Developmental origins of cardiovascular disease: Impact of early life stress in humans and rodents. Neurosci. Biobehav. Rev. 2017;74 (Pt B):453-465. D0I : 10.1016/j. neubiorev.2016.07.018.

11. Reznikov A.G., Nosenko N.D. Eksperimental'noye izucheniye otdalennykh posledstviy perinatal'nogo primeneniya lekarstvennykh sredstv dlya zdorov'ya potomkov. [An experimental study of the long-term effects of perinatal use of drugs on the health of offspring]. Neonatology, Surgery and Perinatal Medicine. 2014;4(1-11):70-78. (In Russian).

12. Sakurai K., Osada Y., Takeba Y. et al. Exposure of immature rat heart to antenatal glucocorticoid results in cardiac proliferation. Pediatr. Int. 2019;61(1):31-42. D0I : 10.1111/ped.13725.

13. Hew K.W., Keller K.A. Postnatal anatomical and functional development of the heart: a species comparison. Birth Defects Res. B. 2003;68(4):09-320.

14. Michas G., Liberman M., Becker K.C. et al. Reciprocal regulation of 11ß-hydroxysteroid dehydrogenase 1 and glucocorticoid receptor expression by dexamethasone inhibits human coronary artery smooth muscle cell proliferation in vitro. Mol. Cell Biochem. 2011;346(12):69-79. D0I : 10.1007/s11010-010-0592-5.

15. Chernyavskiy A.V. Dynamika yaderno-cytoplazmatichnogo vidnoshennya kardiomiocytiv u cerci sh'uriv v rannyomu posstnatalnomu periodi v normi ta experimenti. [The dynamics of nuclear-cytoplasmic index of cardiomyocytes in the heart in the early postnatal period in normal and experimental conditions]. Reports ofVinnitsa National Medical University. 2019; 23(1):89-93. DOI : 10.31393/reports-vnmedical-2019-23(1)-14.

16. Agnew E.J., Ivy J.R., Stock S.J. et al. Glucocorticoids, antenatal corticosteroid therapy and fetal heart maturation. J. Mol. Endocrinol. 2018;61 (1):61-73. DOI : 10.1530/JME-18-0077.

This work is a part of a project "Reactivity of newborn organs after influence of antigens and different nature factors in prenatal period» (2013-2019, state registration 0115U003875) funded by Zaporizhzhia State Medical University.

\section{ORCID and contributionship:}

Olena A. Hryhorieva: 0000-0002-6101-8322 A,D,E,F

Arthur V. Chernyavskiy: 0000-0002-3902-8081 B, C, D

Yuriy Yo. Guminskiy: 0000-0002-8688-9829 E, F

\section{Conflict of interest:}

The Authors declare no conflict of interest.

\section{CORRESPONDING AUTHOR}

Olena A. Hryhorieva

Zaporizhzhia State Medical University

26 Mayakovsky ave., 69035 Zaporizhzhya, Ukraine

tel: +3800505450471

e-mail: elengrig212@gmail.com

Received: 24.03 .2020

Accepted: 16.11 .2020

A - Work concept and design, B - Data collection and analysis, C - Responsibility for statistical analysis,

D-Writing the article, $\mathbf{E}$-Critical review, $\mathbf{F}$ - Final approval of the article 